\title{
Acute myelofibrosis in children with Down's syndrome
}

\author{
D. I. K. EVANS \\ From the Department of Haematology, Royal Manchester Children's Hospital, and \\ Department of Child Health, University of Manchester
}

\begin{abstract}
Evans, D. I. K. (1975). Archives of Disease in Childhood, 50, 458. Acute myelofibrosis in children with Down's syndrome. Two boys with Down's syndrome, recognized at birth, developed acute myelofibrosis at the ages of 19 and 21 months. The disorder presented with anaemia and splenomegaly, and clinically resembled acute leukaemia, but bone marrow histology showed a bizarre pattern with generalized fibrosis, markedly increased reticulin, large reticulum cells, and giant cells resembling megakaryocytes. The children survived 6 and 11 months from diagnosis.

A third case is quoted (Hillman and Forrester, 1968) which was also studied at this hospital; the features of all 3 cases are similar. There appears to be an increased incidence of acute myelofibrosis in children with Down's syndrome, which may be a further example of the instability of the haemopoietic system in this disease. In children with Down's syndrome and unusual leukaemia-like illness, histological examination of the bone marrow may be diagnostic.
\end{abstract}

Idiopathic myelofibrosis is usually a disease of adults, characterized by anaemia and splenomegaly, with a variety of changes in the blood, a slow course, and an irregular increase of fibrosis in the bone marrow (Wintrobe, 1967). This disease may also have an acute termination; however, there is also a type of myelofibrosis which is acute from the outset, without splenomegaly or glandular enlargement, but is rapidly progressive (Lewis and Szur, 1963). The blood shows pancytopenia. The marrow is difficult to aspirate and hypocellular. Trephine biopsy shows increased collagen and reticulin, with primitive reticulum cells and megakaryocytes. Myelofibrosis may also be secondary to polycythaemia vera, or coexist with tuberculosis, malignant disease, and leukaemia.

In childhood, cases of idiopathic myelofibrosis are rare. Secondary myelofibrosis is not uncommon in acute leukaemia, of children as well as of adults, and occurs in both lymphoblastic and granulocytic types (Kundel et al., 1964). In 1969, Tobin, Tan, and Argano noted that 23 cases of myelofibrosis had been reported in children, and gave details of 5 further cases of their own. In each, myelofibrosis accompanied acute leukaemia. 8 of the children reported earlier as cases of myelofibrosis had the

Received 14 November 1974. disorder secondary to leukaemia, but 17 appear to be cases of primary disease. Since 1969, 6 further children have been reported, with features clearly marking them as idiopathic myelofibrosis (Ruhrmann, 1967 (2 cases); Krasilnikoff, 1967; Nagai et al., 1969; Klimova, Indosova, and Zacharova, 1970; Holden et al., 1971). 2 of the reported cases of idiopathic childhood myelofibrosis have also had Down's syndrome (Rosenberg and Taylor, 1958; Hillman and Forrester, 1968). 2 more had different chromosome abnormalities affecting a clone of cells: group C monosomy (Holden et al., 1971) and a Philadelphia chromosome (Maas and Ruhrmann, 1971). Adult myelofibrosis has also been reported in families, affecting father and daughter twice (Decastello, 1954; Bernard et al., 1967) and 2 brothers (Patakfalvi, Csete and Horváth, 1969), suggesting that other genetic factors may sometimes be involved.

Two further cases of idiopathic childhood myelofibrosis of the acute type are reported here: both children also had Down's syndrome. Thus, of 25 children with idiopathic myelofibrosis, 4 have had Down's syndrome. Acute myelofibrosis may occur with unusual frequency in Down's syndrome: it appears to be another example of the propensity of patients with this disease to develop abnormalities of blood and bone marrow. 


\section{Case reports}

Case 1. In 1971 a boy who had been noted at birth to have Down's syndrome with trisomy-21 and a cardiac murmur was found to be anaemic at the age of 18 months. He was pale, with a systolic murmur down the left sternal edge. The spleen was just palpable. Haemoglobin was $7.8 \mathrm{~g} / \mathrm{dl}$, white cells $3300 / \mathrm{mm}^{3}$ (neutrophils $5 \%$, lymphocytes $53 \%$, monocytes $40 \%$, normoblasts $2 \%$ ), and platelets $51000 / \mathrm{mm}^{3}$, i.e. pancytopenia. Two bone marrow aspirates were diluated with blood and showed reduced granulopoiesis. $50 \%$ of the nucleated cells were normoblasts and only $17 \%$ were granulocytes, with $26 \%$ lymphocytes and $1 \%$ blast cells. $X$-rays showed translucency in the lower femora and upper tibiae suggesting leukaemia, but the diagnosis was not supported by the bone marrow aspirates. A trephine sample showed generalized hypoplasia with increased reticulin and fibroblasts: there was no increase of leukaemic blast cells. He was treated with prednisolone 15 $\mathrm{mg} /$ day without improvement. He developed a chest infection and died at the age of 20 months, 6 months after the onset of the illness. Full necropsy was not performed, but a bone marrow sample was removed for histology. It showed generalized bony fibrosis with increased collagen and reticulin together with some reticulum cells and multinucleated cells resembling megakaryocytes (Fig. 1).
Case 2. In 1955 a male was noted to have Down's syndrome at birth. At 21 months of age he became ill and refused to walk. In hospital he was found to be anaemic and was given iron. 6 weeks later the left elbow and both feet swelled. Haemoglobin was $7 \cdot 4$ g/dl, white cells $5800 / \mathrm{mm}^{3}$ (neutrophils $47 \%$, lymphocytes $49 \%$, eosinophils $5 \%$, monocytes $3 \%$ ). Clear fluid was aspirated from the left elbow, and he was given ascorbic acid. A month later $x$-ray of the elbow showed osteoporosis. Penicillin and erythromycin were ineffective. He became more anaemic, haemoglobin $5.5 \mathrm{~g} / \mathrm{dl}$, white cells $10500 / \mathrm{mm}^{3}$ (neutrophils $33 \%$, lymphocytes $67 \%$ ), platelets $167000 / \mathrm{mm}^{3}$. A month later purpura developed with platelets $63000 / \mathrm{mm}^{3}$ Later $x$-rays showed marked osteoporosis and widespread periosteal elevation. 8 months after the initial admission to hospital he had a distended abdomen with hepatosplenomegaly and enlarged nodes in the neck and inguinal regions. Haemoglobin was $3.7 \mathrm{~g} / \mathrm{dl}$, white cells $7300 / \mathrm{mm}^{3}$ (neutrophils $15 \%$, lymphocytes $40 \%$, normoblasts $20 \%$, megaloblasts $8 \%$, blast cells $11 \%$ ). He died at the age of 32 months, 11 months after onset of the illness. Apart from antibiotics, no treatment was given.

Necropsy showed generalized glandular enlargement and hepatosplenomegaly. The spleen weighed $60 \mathrm{~g}$. The bone marrow was replaced with hard white fibrous

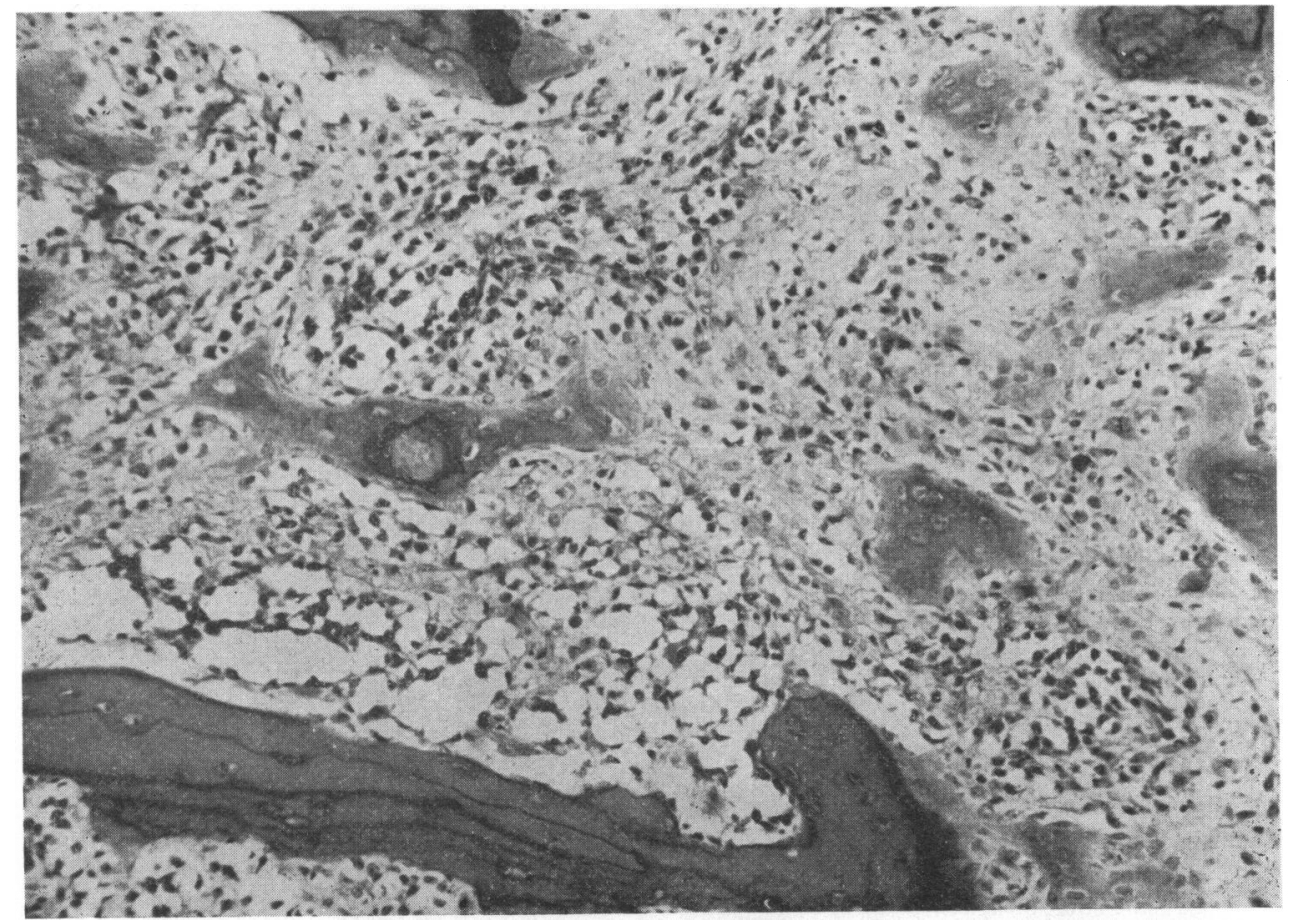

Fig. 1.-Case 1. Bone marrow section showing fibrous tissue, a pleomorphic cellular infiltrate including reticulum cells and megakaryocytes, and fat. (Haematoxylin and eosin. $\times 120$.) 
tissue. Sections showed infiltration with primitive reticulum cells and giant cells resembling megakaryocytes. There was some necrosis and patchy fibrosis. The spleen showed marked haemosiderosis, and was infiltrated with primitive cells and haemopoietic cells. Similar changes were found in the lymph nodes (Fig. 2 and 3). No cytogenetic studies were performed.

\section{Discussion}

Both these children had Down's syndrome and died with a myeloproliferative disorder showing bone marrow fibrosis. Case 1 survived 6 months with pancytopenia. Bone marrow biopsy showed fibrosis and no evidence of leukaemia, and the find-

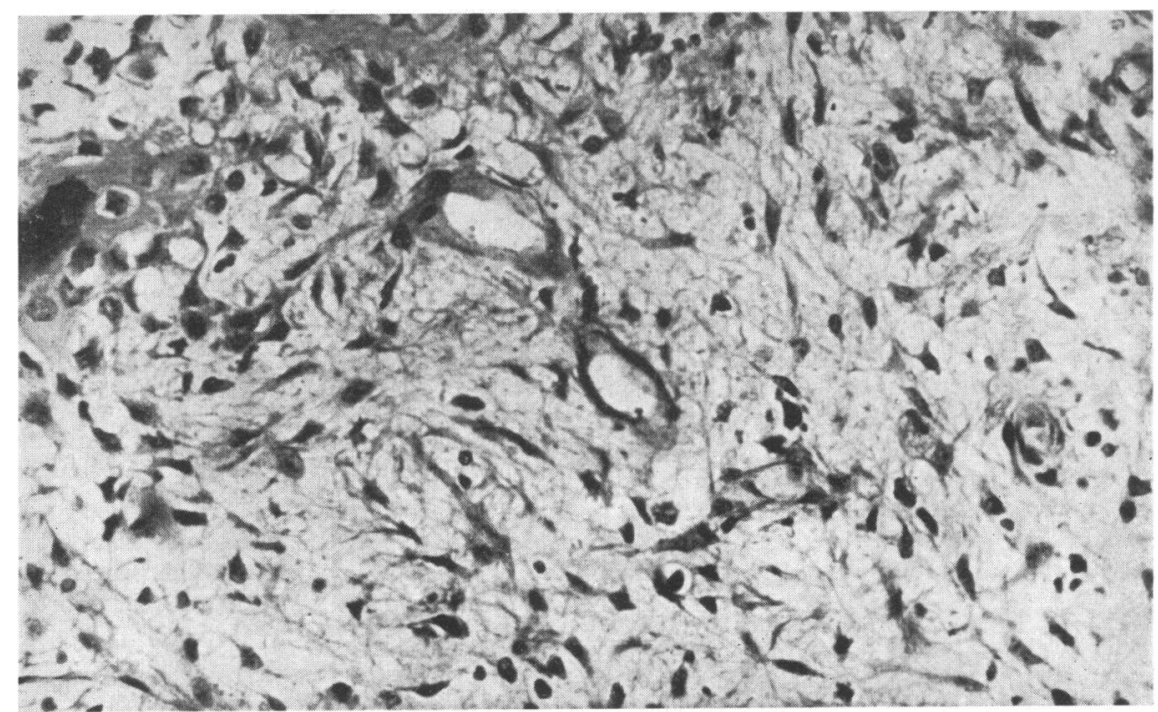

Fig. 2.-Case 2. Bone marrow section shows similar changes to Case 1, with more marked fibrosis. (Haematoxylin and eosin. $\times 262$.)

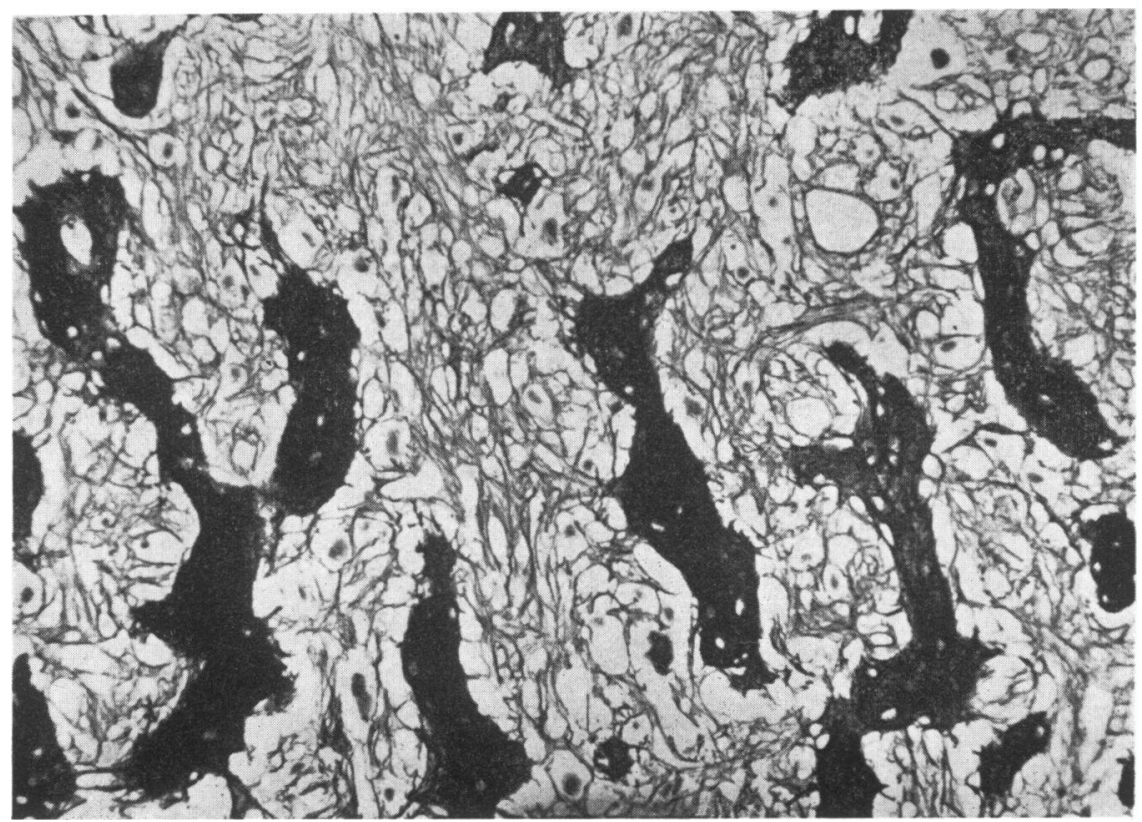

FIG. 3.-Case. 2. Bone marrow section shows a dense pattern of reticulin fibres. $(\times 108$. 
ings were confirmed after death. The clinical picture resembles the acute myelofibrosis described by Lewis and Szur (1963) with pancytopenia, hypocellular marrow aspirates, and a rapid course. Case 2 had a disease lasting 11 months, with lymph node enlargement, hepatosplenomegaly, and blast cells in the blood at the time of death, suggesting a leukaemic picture, but with fibrotic tissue instead of leukaemic cells in the marrow. This case is similar to the case of Hillman and Forrester (1968), a girl with Down's syndrome who died with features resembling acute leukaemia clinically, in whom necropsy showed only myelofibrosis. The case was also investigated at this hospital, and thus 3 children with Down's syndrome and acute myelofibrosis have been seen in Manchester since 1958. The disorder is clearly different from acute leukaemia, as the bone marrow shows no infiltration with leukaemic cells but is markedly fibrosed and contains large cells resembling primitive reticulum cells and other cells resembling megakaryocytes.

Myelofibrosis is usually included among the myeloproliferative disorders originally described by Dameshek (1951). They have been described in children, but are rare. A number of myeloproliferative conditions have been reported in neonates with Down's syndrome, for example, neonatal erythrocytosis (Weinberger and Oleinick, 1970), leukaemoid reaction with polycythaemia (Miller, Sherrill, Hathaway, 1967; Pochedly and Ente, 1968) or with megakaryocyte proliferation (Fujinami et al., 1961). Better known is the syndrome of ineffective granulopoiesis masquerading as acute leukaemia (Ross, Maloney, and Desforges, 1963). A wide variety of changes has been described in the blood of these patients, many of which, including increased activity of certain leucocyte and red cell enzymes, are probably secondary to increased cell turnover, while other changes, including changes in immunoglobulins, are probably secondary to increased infections (Woodford and Bearn, 1970). The abnormal response of their lymphocytes to phytohaemagglutinin (Hayakawa et al., 1968; Mellmann, Younkin, and Baker, 1970) or in mixed lymphocyte culture (Sasaki and Obara, 1969) may explain, at least in part, this increased susceptibility to infection. The association of Down's syndrome and leukaemia is well known (Krivit and Good, 1957).

The Manchester Children's Tumour Registry recorded 616 cases of leukaemia from 1954 to 1972, and there were 5 children with Down's syndrome included in the 465 cases presenting between 1954 and 1968. No cases of myelofibrosis are known to have arisen in normal children during this time. 3 cases of myelofibrosis in Down's syndrome have occurred during a time when 616 children have presented with leukaemia: so one child with Down's syndrome and myelofibrosis has presented for every 200 cases of leukaemia. If the incidence of this combination of disorders were general, clearly far more cases would be known. This is not the case. Either our experience is exceptional or the condition is under-reported and presumably underdiagnosed, because histological examination of the bone marrow is not done. Trephine biopsy enabled a diagnosis to be made in both the cases in which it was done; and the diagnosis was confirmed after death.

The clinical and pathological syndrome of childhood myelofibrosis has varied. The first case of Rosenberg and Taylor (1958) had Down's syndrome and showed pleomorphic and bizarre cellular infiltration with haemosiderosis in the spleen, as did one of the cases described here (Case 2). The patient of Hillman and Forrester (1968) developed thrombocytosis before death, and a raised platelet count was found in the cases of Fujinami et al. (1961) and Nagai et al. (1969). Though the case described by Klimova et al. (1970) survived 14 years, all the children with myelofibrosis and Down's syndrome have died with a rapidly progressive illness. Unlike the children with Down's syndrome and a leukaemia-like illness first described by Ross et al. (1963), there has been no recovery.

It should not be assumed that the blast cells in the blood of these children must be leukaemic myeloblasts or lymphoblasts. Chervenick (1972) has shown that an increased number of stem cells circulate in the blood of patients with myelofibrosis. The blast cells in children with Down's syndrome and myelofibrosis may be stem cells in exceptional numbers as a result of the impaired regulation similar to that responsible for the transient abnormality of granulopoiesis. Breton Gorius et al. (1973) showed that circulating blast cells in a case of acute myelofibrosis with thrombocytosis were micromegakaryoblasts, and the blast cells in other cases may have a similar origin. Abnormal megakaryocytes are present in increased numbers, and thrombocytosis has been a feature of some cases.

Many disturbances of haemopoiesis have been described in Down's syndrome. It seems likely that there is an instability in the control of bone marrow proliferation resulting in the temporary disorders of the neonatal period, the increased incidence and earlier onset of childhood leukaemia, and the myeloproliferative disorders described here. 
I am grateful to Dr J. K. Steward for information from the Manchester Children's Tumour Registry, and to Dr. H. B. Marsden for further material and Russian translations. Drs. M. H. Buston, K. M. Hunt, and P. Morris Jones provided details and material from Case 1. Part of this work was supported by a grant from the Leukaemia Research Fund.

\section{REFERENCES}

Bernard, J., Seligmann, M., Loirat, Ch., Chassigneux, J., Basch, A. and Gueudet, A. (1967). Splenomégalie myéloïde familiale. Nouvelle Révue Française d'Hématologie, 7, 499.

Breton Gorius, J., Daniel, M. T., Flandrin, G., and Kinet Denoel, G. (1973). Fine structure and peroxidase activity of circulating micromegakaryoblasts and platelets in a case of acute myelofibrosis. British Fournal of Haematology, 25, 331.

Chervenick, P. A. (1972). Increased number of stem cells in blood of patients with myelofibrosis. (Abst.) Blood, 40, 935

Dameshek, W. (1951). Some speculations on the myeloproliferative syndrome. Blood, 6, 372.

Decastello, A. (1954). Osteomyelosklerose bei Vater und Tochter. Wiener Klinische Wochenschrift, 66, 655.

Fujinami, T., Sugiyama, T., Tankawa, H., and Uesugi, Y. (1961). A case of megakaryocytic myelosis in a child. Annales Paediatrica faponica, 7, 226.

Hayakawa, H., Matsui, I., Higurashi, M., and Kobayashi, N. (1968). Hyperblastic response to dilute P.H.A. in Down's syndrome. Lancet, 1, 95.

Hillman, F., and Forrester, R. M. (1968). Myelofibrosis simulating acute leukaemia in a female infant with Down's syndrome. Irish Fournal of Medical Science, 1, 7th series, 167.

Holden, J. D., Garcia, F. U., Samuels, M., Dupin, C., Stallworth, B., and Anderson, E. (1971). Myelofibrosis with C monosomy of marrow elements in a child. American fournal of Clinical Pathology, 55, 573.

Klimova, N. F., Indosova, E. N., and Zacharova, A. V. (1970). Idiopathic myelofibrosis developing in early childhood Problemi Gematologi and Perilevanyi Krovi, 15, No. 6, 52.

Krasilnikoff, P. A. (1967). Myelofibrosis and myeloid leukaemia. Acta Paediatrica Scandinavica, 56, 424.

Krivit, W., and Good, R. A. (1957). Simultaneous occurrence of mongolism and leukemia: report of a nationwide survey. American fournal of Diseases of Children, 94, 289.

Kundel, D. W., Brecher, G., Bodey, G. P., and Brittin, G. M. (1964). Reticulin fibrosis and bone marrow infarction in acute leukemia. Implications for prognosis. Blood, 23, 526.
Lewis, S. M., and Szur, L. (1963). Malignant myelosclerosis. British Medical fournal, 2, 472.

Maas, B., and Ruhrmann, G. (1971). Verlauf einer Osteomyelofibrose seit dem Säuglinsalter. Monatsschrift für Kinderheilkunde, $119,56$.

Mellman, W. J., Younkin, L. H., and Baker, D. (1970). Abnormal lvmphocyte function in trisomy 21. Annals of the New York Academy of Sciences, 171, 537.

Miller, J. McC., Sherrill, J. G., and Hathaway, W. E. (1967). Thrombocythemia in the myeloproliferative disorder of Down's syndrome. Pediatrics, 40, 847.

Nagai, K., Sugiyama, Y., Isono, Y., and Yoshida, K. (1969). An autopsy case of primary osteomyelosclerosis in a 6-year old girl. Acta Pathologica faponica, 19, 81.

Fatakfalvi, A., Csete, B., and Horváth, T. (1969). Familial myelofibrosis. Haematologia, 3, 217.

Fochedly, C., and Ente, G. (1968). Disseminated intravascular coagulation in a newborn with Down's syndrome. Fournal of Pediatrics, 73, 298.

Rosenberg, H. S., and Taylor, F. M. (1958). The myeloproliferative syndrome in children. Fournal of Pediatrics, 52, 407.

Ross, J. D., Maloney, W. C., and Desforges, J. F. (1963). Ineffective regulation of granulopoiesis masquerading as congenital leukemia in a mongoloid child. Fournal of Pediatrics, 63, 1.

Ruhrmann, G. (1967). Myelotomy in obscure infantile anaemias, performed in two cases of infantile myelofibrosis. Blut, 15, 89 .

Sasaki, M., and Obara, Y. (1969). Hypersensitivity of lymphocytes in Down's syndrome shown by mixed lymphocyte culture experiments. Nature, 222, 596.

Tobin, M. S., Tan, C., and Argano, S. A. P. (1969). Myelofibrosis in pediatric age group. New York State fournal of Medicine, 69, 1080.

Weinberger, M. M., and Oleinick, A. (1970). Congenital marrow dysfunction in Down's syndrome. Fournal of Pediatrics, 77, 273.

Wintrobe, M. M. (1967). Clinical Hematology, 6th ed. Lea and Febiger, Fhildelphia.

Woodford, F. P., and Bearn, A. G. (1970). A critical examination of some reported biochemical abnormalities in mongolism. Annals of the New York Academy of Sciences, 171, 551.

Correspondence to Dr. D. I. K. Evans, Royal Manchester Children's Hospital, Pendlebury, Manchester M27 1HA. 